Human Ethology Bulletin 31 (2016)2: 1 - 4

Letter from the Editorial Board

\title{
ROLE MODELS - HOW WE MAKE THEM AND WHY WE FOLLOW THEM
}

\section{Elisabeth Oberzaucher Editor in Chief}

The imitation of the behaviour of role models is a very common phenomenon in humans and nonhuman animals. Biologists call this behaviour social learning. Social learning is characterised by a number of advantages compared to other forms of learning: Other than in trial and error learning, you do not have to try everything by yourself and can thus avoid a lengthy and costly process. And you depend less on your own mental and creative capacities than insightful learning would require. By imitating the behaviour of a role model, we take an efficient shortcut to adopt innovations, both on the behavioural and cognitive level.

Not everyone in our surroundings is likely to be adopted as a role model. Who is considered as a potential role model depends on a number of factors. (Lonsdorf \& Bonnie, 2010)

Role model orientation changes over life history. In early childhood, the parents have the strongest impact on the behaviour of their children. This is why they cannot apply double standards when it comes to their own and their child's behaviour: Studies have shown that children will adopt a healthy nutrition style only if their parents eat healthy, too. If you dislike vegetables and cannot hide this from your child, it is unlikely that you will convince your child to do otherwise (Draxten, Fulkerson, Friend, Flattum \& Schow, 2014). Those who are closest to us socially have the strongest impact on our behaviour. The parental influence decreases as their children grow older. The social orientation shifts toward peers. During puberty, the goal is to establish oneself in the own social circle, and members of that circle are the most important role models. As we grow up, our focus tends to be directed more and more at people outside the immediate social circle.

Today we preferentially choose people who are well-known as role models. Why is that so? Being a public figure seems to be helpful for people to become role models. It does not suffice to do remarkable things, it seems to be just as necessary to make sure that others hear about it. This is why the media presence of individuals plays an important role for their 
ability to become role models. People who are widely known command a substantial amount of attention, and likely will be heard, even if talking about things they are not qualified to talk about. Leonardo DiCaprio recently became a hero on social media for using his own publicity to rally people to behave more sustainably. He became a role model neither through qualification nor through exceptionally sustainable behaviour, but because he is a popular person. Visibility seems to be the most important, sometimes even the only necessary factor that makes a person a likely role model. This phenomenon seems to be related to another psychological effect: We prefer things that we know, and increased exposure to a stimulus will increase our preference for it (Zajonc, 1968). Akin to the mere exposure effect, familiarity with a person seems to affect our choice of role models, too.

Visibility on mass media increases the credibility of persons far beyond the limits of their competences and makes them thought leaders for no other reason than their popularity. This phenomenon arises from a mismatch between the environment of evolutionary adaptedness and today's life. Through mere exposure to stars via mass media we develop something akin to social relationships to those people. We see them often, they visit us in our living room, we know a lot of personal details about them. This kind of familiarity was limited to group members in our evolutionary past. In the EEA, it was a sensible decision not to adopt just anyone as a role model, but be a bit more selective. Familiarity increases the effectiveness of role models not only in humans. In nonhuman animals, social learning is often limited to learning from familiar individuals. Strangers do not command the trustworthiness of a familiar group member, and therefore they are likely discarded as potential role models. The pseudo-familiarity with stars thus increases their suitability as role models. Real experts, on the other hand, who could competently inform about specific topics, can rarely count on this familiarity bonus. Paradoxically, we believe those people, who are objectively more knowledgeable, less than people we know, or even only assume to know.

Commercials make use of this phenomenon: Stars vouch for all kinds of products. There is actually no good reason why we should believe that a certain actor knows more about coffee than the rest of us, but companies are happy to pay large amounts of money to secure such credentials. Even if commercials built upon the voice of experts, they do not what would be scientifically valid: Rather than gathering the opinions of a large number of professionals, they establish one expert and foster this person's familiarity. While this strategy requires a long-term approach, it can be very successful on the long run. (Grimes \& Kitchen, 2007)

Communicative skills seem to be essential for today's role models. In order to communicate a message successfully, it is necessary to do so in a language that is accessible to a large population. This is often easier for people who are used to publicity than for experts. The more superficial knowledge of topics they are asked to voice their opinion on makes it easier for them to phrase their message straightforward. Especially scientists often have the opposite problem: As their knowledge of their field is full of details and nuances, it is hard for them to communicate in a concise and understandable way. Extracting the main 
essence of a scientific study sometimes appears to be sheer impossible. When we consider our own sciences that produce likelihoods and distributions as results, we are well aware that clear-cut statements are doing our findings injustice. A scientist communicating to the general public thus has to tread a thin line between trying not to oversell their findings, and at the same time communicating in a digestible way. (Orwell, 1946)

The mechanisms that are applied in the choice of role models and in the assessment of their credibility developed during our evolutionary past under conditions that were very different from our living conditions today. Our ancestors could increase the effectiveness of social learning processes by preferring to learn from familiar individuals. Modern technologies generate a pseudo-familiarity with people whom we do not actually know. Those people who are frequent visitors in our lives through mass media exposure become virtual group members. This is why we believe them and choose them to be our role models. This results in the danger that we might trust the wrong people, those persons whom we think to know, and therefore assume to be trustworthy, despite their being quite the opposite. By being aware of the roots of this intuitive feeling of trust, we can try to counteract this on a conscious level.

These effects have implications far beyond affecting our consumer behaviour. If mere exposure is maximised through presence in mass media and combined with ways of communication that put messages in simple, easy to grasp words, we might respond on an intuitive level to people who we would not follow otherwise. These mechanisms open doors to thought leaders and politicians who command enough money to buy presence in mass media. It is still an open question whether social media emphasise or counteract this effect. If we increase familiarity with a person through sharing our outrage about this person, we are somehow trapped. Should we really share pictures of the object of our outrage, or images of the alternative? Could the knowledge we have about the evolutionary basis of human perception, cognition and behaviour be helpful in informing us about better ways to communicate via modern technologies.

Considering these phenomena in the light of evolution might be informative and provide answers to these questions.

The current issue of the Human Ethology Bulletin is exemplary for the broadness of our field and for the diversity of the members of the International Society for Human Ethology. Dunkel, Gladden and Mathes (2016) target morality and moral reasoning in their research article and argue that sex differences are due to differential evolutionary selection pressures. Farsang and Kocsor (2016) investigated the young male syndrome by analysing data on homicides in two cultures. Grueter, Johnson, Leaning, Tan, Jones and Peris (2016) provide new insights into why escalations in sports competitions happen. Wade and Feldman (2016) elaborate on the mechanisms and tactics employed in flirtatious behaviour and found empirical support for the evolutionary-based hypotheses. The articles published in this issue illustrate the usefulness of evolutionary theory in providing guidance for research on human behaviour, psychology and cognition. 


\section{REFERENCES}

Draxten, M., Fulkerson, J.A., Friend, S., Flattum, C.F. \& Schow, R. (2014). Parental role modeling of fruits and vegetables at meals and snacks is associated with children's adequate consumption. Appetite 78,C, 1-7. DOI

Dunkel, S.C., Gladden, P.R. \& Mathes, E.W. (2016). Sex Differences in Moral Reasoning: The Role of Intelligence and Life History Strategy Human Ethology Bulletin, 31, 2, 5-16. DOI

Farsang, P. \& Kocsor, F. (2016). The Young Male Syndrome Revisited - Homicide Data from Hungarian and Australian Populations. Human Ethology Bulletin, 31, 2, 17-29. DOI

Grimes, Anthony; Kitchen \& Phillip J. (2007). Researching mere exposure effects to advertising: Theoretical foundations and methodological implications. International Journal of Market Research 49 (2): 191-221.

Grueter, C.C., Johnson, L., Leaning, M., Tan, M. J., Jones, Z. \& Peris, J. (2016). An Evolutionary View on Conflict Escalation in Team Sports Competitions. Human Ethology Bulletin, 31, 2, 45-51. DOI

Orwell, G. (1946). Politics and the English Language. Horizon, London. retrieved from https://faculty.washington.edu/rsoder/EDLPS579/HonorsOrwellPoliticsEnglishLanguage. pdf on June 13th 2016.

Wade, T.J. \& Feldman, A. (2016). Sex and the Perceived Effectiveness of Flirtation Techniques. Human Ethology Bulletin, 31, 2, 30-44. DOI

Zajonc, Robert B. (1968). Attitudinal Effects Of Mere Exposure. Journal of Personality and Social Psychology, 9 (2, Pt.2): 1-27. DOI 